\title{
Identificação e caracterização de bactérias potencialmente patogênicas isoladas de duas praias do litoral norte de Pernambuco
}

Identification and characterization of potentially pathogenic bacteria isolated from two beaches on the northern coast of Pernambuco

Identificación y caracterización de bacterias potencialmente patógenas aisladas de dos playas de la costa norte de Pernambuco

\author{
Alison Rodrigues dos Santos \\ ORCID: https://orcid.org/0000-0002-7483-3887 \\ Centro Universitário São Miguel, Brasil \\ E-mail: alisonsantos008@gmail.com \\ Helen Christine de Oliveira \\ ORCID: https://orcid.org/0000-0001-6028-3741 \\ Centro Universitário São Miguel, Brasil \\ E-mail: helenchristine98@hotmail.com \\ Alicya Maria da Conceição Silva \\ ORCID: https://orcid.org/0000-0002-2002-6553 \\ Centro Universitário São Miguel, Brasil \\ E-mail: alicyamarie51@gmail.com \\ Rayssa Rosendo Alves \\ ORCID: https://orcid.org/0000-0003-3638-167X \\ Centro Universitário São Miguel, Brasil \\ E-mail: rayssa15.ra76@gmail.com \\ Beatriz Rayana Damásio de Andrade \\ ORCID: https://orcid.org/0000-0002-1454-344X \\ Universidade Federal Rural de Pernambuco, Brasil \\ E-mail: beatrizdamasio54@gmail.com \\ Maria Luiza Ribeiro Bastos da Silva \\ ORCID: https://orcid.org/0000-0002-8406-9472 \\ Centro Universitário São Miguel, Brasil \\ E-mail: luizabastos6@yahoo.com.br
}

\begin{abstract}
Resumo
Pernambuco possui uma grande disponibilidade de energia solar e altas temperaturas, e é bastante conhecido pela beleza natural de suas praias, que são frequentadas para a realização de atividades de lazer, como: passeios, mergulhos, aulas de natação e a realização de diversos esportes. Com isso, as praias acabam se tornando um ambiente de grande circulação contribuindo para o impacto dos ecossistemas, além desse fator podemos relatar a expansão das indústrias, pecuária, agricultura e centros urbanos. O conjunto desses fatores influenciam na ascensão da taxa de contaminação da areia, em razão do descarte de resíduos inorgânicos nas praias ou os que são trazidos pela água do mar. Desta forma, o presente estudo objetivou identificar e caracterizar bactérias potencialmente patogênicas isoladas nas praias de Itamaracá e Olinda, do litoral norte de Pernambuco. As coletas foram realizadas nos meses de janeiro e maio, onde foram retiradas amostras de areias úmidas e seca correspondentes a $10 \mathrm{~cm}$ e a $20 \mathrm{~cm}$ de profundidade, no qual posteriormente passaram por um processo de suspensão em água fosfatada e diluídas a 10-3 que por sequência foram semeadas em meio Ágar sangue. Os isolados bacterianos, foram submetidos a testes bioquímicos, teste de Gram e catalase. Na praia de Olinda, foi identificada a existência das bactérias Escherichia coli, Staphylococcus spp, Staphylococcus aureus, Streptococcus spp e Vibrio cholerae. Na praia de Itamaracá foi identificada a existência da Escherichia coli, Klesbsiella pneumonia, Staphylococcus spp, Staphylococcus aureus, Streptococcus spp e Vibrio cholerae. Contudo, as análises microbiológicas mostraram que existe um alto nível de contaminação na areia de praia, principalmente na areia seca onde tem maior contato com os banhistas. Portanto, é necessário um monitoramento da areia para garantir uma qualidade sanitária.
\end{abstract}

Palavras-chave: Contaminação; Litoral Pernambucano; Bactérias patogênicas.

\footnotetext{
Abstract

Pernambuco has a large availability of solar energy and high temperatures, and is well known for the natural beauty of its beaches, which are frequented for leisure activities, such as: walks, diving, swimming lessons and the performance
} 
of various sports. With this, the beaches end up becoming an environment of great circulation, contributing to the impact of ecosystems, in addition to this factor we can report the expansion of industries, livestock, agriculture, and urban centers. All these factors influence the rise in the rate of sand contamination, due to the disposal of inorganic waste on the beaches or that brought by seawater. Thus, the present study aimed to identify and characterize potentially pathogenic bacteria isolated on the beaches of Itamaracá and Olinda, on the northern coast of Pernambuco.The bacterial isolates were submitted to biochemical tests, gram test and catalase. At Olinda beach, the bacteria Escherichia coli, Staphylococcus spp, Staphylococcus aureus, Streptococcus spp and Vibrio cholerae were identified. At Itamaracá beach, Escherichia coli, Klesbsiella pneumonia, Staphylococcus spp, Staphylococcus aureus, Streptococcus spp, and Vibrio cholerae were identified. However, the microbiological analyses showed that there is a high level of contamination in the beach sand, especially in the dry sand where there is more contact with bathers. Therefore, a monitoring of the sand is necessary to guarantee a sanitary quality.

Keywords: Contamination; Urban beaches; Pathogenic bacteria.

\section{Resumen}

Pernambuco tiene una gran disponibilidad de energía solar y altas temperaturas, y es conocido por la belleza natural de sus playas, que son frecuentadas para actividades de ocio, como: paseos, buceo, clases de natación y diversos deportes. Con esto, las playas acaban convirtiéndose en un entorno de gran circulación contribuyendo al impacto de los ecosistemas, además de este factor podemos reportar la expansión de las industrias, la ganadería, la agricultura y los centros urbanos. Todos estos factores influyen en el aumento de la tasa de contaminación de la arena, debido al vertido de residuos inorgánicos en las playas o a los aportados por el agua del mar. Así, el presente estudio tuvo como objetivo identificar y caracterizar bacterias potencialmente patógenas aisladas en las playas de Itamaracá y Olinda, en la costa norte de Pernambuco. Los aislados bacterianos fueron sometidos a pruebas bioquímicas, prueba de Gram y catalasa. En la playa de Olinda se identificaron las bacterias Escherichia coli, Staphylococcus spp, Staphylococcus aureus, Streptococcus spp y Vibrio cholerae. En la playa de Itamaracá se identificaron Escherichia coli, Klesbsiella pneumonia, Staphylococcus spp, Staphylococcus aureus, Streptococcus spp y Vibrio cholerae. Sin embargo, los análisis microbiológicos mostraron que hay un alto nivel de contaminación en la arena de la playa, principalmente en la arena seca, donde hay un mayor contacto con los bañistas. Por lo tanto, es necesario controlar la arena para garantizar su calidad sanitaria.

Palabras clave: Contaminación; Playas urbanas; Bacterias patógenas.

\section{Introdução}

Os elementos bióticos e abióticos têm sofrido impactos gerados pelo aumento populacional das últimas décadas. A poluição de ambientes urbanos por agentes biológicos é um dos resultados da urbanização (Lescreck et al., 2016). A falta de planejamento em relação ao tratamento e destinação dos resíduos sólidos descartados nas areias das praias e a destinação dos efluentes líquidos são o principal fator de contaminação dessas praias, gerando assim diversas problemáticas para o ambiente e as pessoas que frequentam o local (Souza et al., 2015).

As praias são ambientes cada vez mais procurados para a realização de atividades de lazer, como: passeios em família, mergulhos, aulas de natação e a realização de diversos esportes, além da pesca e do turismo que, em alguns municípios, são as principais fontes de renda das famílias, sendo necessária a avaliação sanitária desses ecossistemas para que se tenha um controle de qualidade das atividades realizadas nas praias (Destro et al., 2020).

Por meio de contato social e da comercialização, que ajuda no crescimento econômico da região, as ações antropológicas geradas podem acometer crianças e adultos que frequentam esse local, sendo necessário realizar ações preventivas para uma melhor qualidade das areias das praias, para que se possa garantir uma melhor segurança e uma boa qualidade desses ambientes (Silva et al., 2020).

$\mathrm{Na}$ areia existe uma grande variedade de microrganismos, principalmente nas praias que ficam localizadas próximas a áreas urbanas e indústrias, pois atraem um maior número de banhistas, que por consequência torna-se uma problemática para os órgãos públicos, atraindo assim um maior número de banhistas (Monteiro et al., 2015). Visto que, muitos microrganismos patógenos são hidrófilos, ou seja, se propagam em águas utilizadas para recreação pelos banhistas o que facilita possíveis infecções (Nogueira, 2016), a água e a areia se tornam meios propícios para o cultivo e a disseminação das doenças causadas por esses microrganismos (França et al., 2018). 
A expansão das indústrias, da pecuária, da agricultura e dos centros urbanos contribui para a ascensão da taxa de contaminação dos mares, rios, lagos e reservatórios, que acontece através de variados compostos orgânicos sintéticos, chamados de compostos emergentes. Existem mais de 3 milhões desses compostos orgânicos sintéticos e pressupõe-se que são produzidos cerca de 100 mil desses compostos regularmente, sendo assim em um ano são produzidas 200 milhões de toneladas e cerca de 20 a 30\% chegam aos ambientes aquáticos (Borges et al., 2016).

Com a chegada destes compostos nos ambientes aquáticos, a contaminação é ampliada para as areias, ocasionando assim problemas de saúde pública, sendo necessário o conhecimento dos agentes patológicos presentes na areia, pois esses agentes podem acometer as pessoas que frequentam esses ambientes e começarem a desenvolver problemas de saúde graves (Cicero et al., 2012), já que as areias possuem uma quantidade maior de microrganismos patógenos do que a água, atuando como reservatório para esses microrganismos e contribuindo com a dispersão desses genes resistentes, que apresentam riscos à saúde pública, pois não há um monitoramento dessas areias (Andrade et al., 2015).

Compreende-se que as bactérias são microrganismos procariontes e unicelulares, ou seja, não podem ser vistas a olho nu. Esses organismos podem ser tanto patógenos quanto benéficos e têm uma grande importância ecológica. As bactérias patogênicas tendem a ser um problema de saúde pública, devido a sua ampla ação infecciosa. Nos dias atuais existe uma grande demanda de pessoas que frequentam a praia no verão, portanto a tendência é aumentar a contaminação do meio ambiente. Devido a diversidade de microrganismos presente no solo e condições diversas para a manutenção dos mesmos no ambiente, pode ser observado alterações no quantitativo de bactérias presentes em uma determinada área em virtude das variações presentes nos períodos dos anos (Lescreck et al., 2016).

Assim, é de grande importância a avaliação das praias para que tenha o conhecimento sobre descarte correto do lixo e através disso sejam tomadas medidas preventivas, para que não haja a contaminação do ecossistema. Sendo assim, o presente estudo objetivou identificar e caracterizar bactérias potencialmente patogênicas isoladas nas praias de Itamaracá e Olinda, litoral norte de Pernambuco.

\section{Metodologia}

As áreas de estudo incluíram os municípios Olinda e Itamaracá, situadas no Litoral Norte de Pernambuco. No qual apresentam um clima tropical úmido, com uma temperatura média anual de 25 a $30^{\circ} \mathrm{C}$. A região é caracterizada por apresentar duas estações bem definidas: período seco, que ocorre nos meses mais quentes (setembro a fevereiro), e período chuvoso que ocorre durante os meses com temperaturas mais amenas (março a agosto) (Pereira et al., 2017). Na praia de Olinda a coleta foi realizada na praia do quartel, coordenadas: latitude -7,9947220, Longitude -34.8377880 (Figura 1).

Figura 1 - Praia do Quartel, município de Olinda - PE.

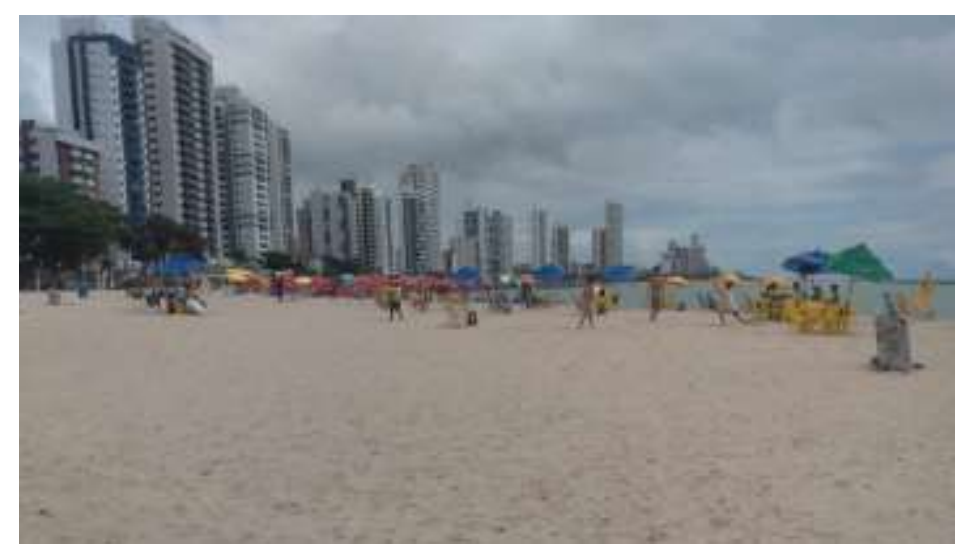

Fonte: Autores (2021). 
A coleta no município de Itamaracá, foi realizada na praia de Jaguaribe com as coordenadas geográfica latitude: 7,7295630 e longitude $-34,8256850$, considerada de alta afluência de público e por apresentar maior risco potencial à saúde dos banhistas, em virtude da contaminação da água do mar, devido ao despejo incorreto do esgoto sanitário (Figura 2):

Figura 2 - Praia de Jaguaribe, município de Itamaracá - PE.

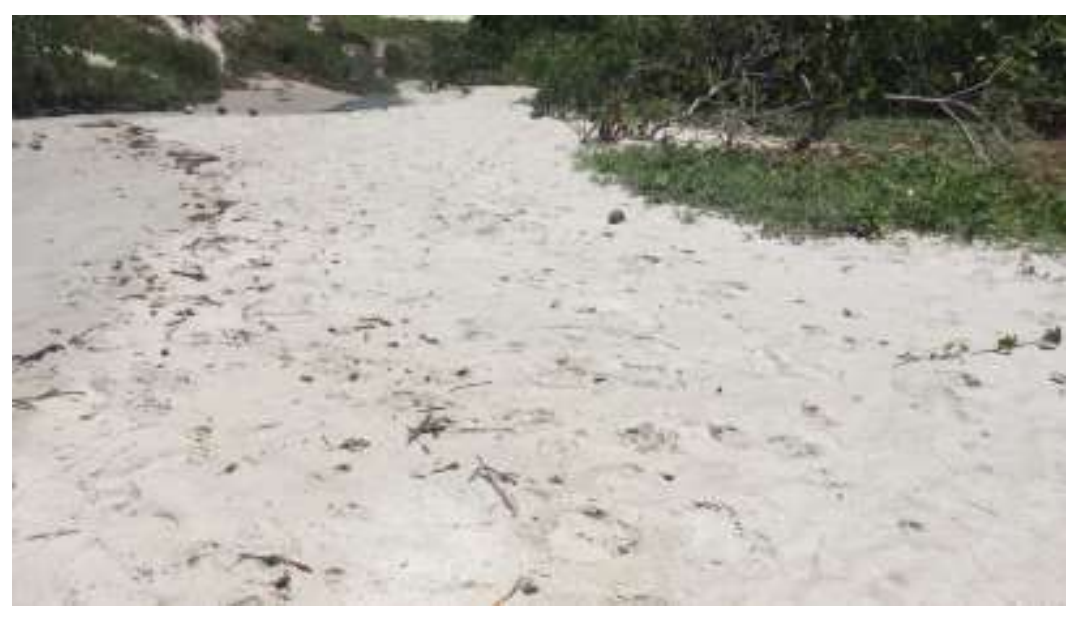

Fonte: Autores.

Foram realizadas duas coletas em períodos diferentes, a primeira foi executada no mês de janeiro e a outra no mês de maio de 2021. Em cada praia foi coletada duas amostras de areia (seca e úmida) para caracterizar duas zonas distintas da praia: zona seca, que normalmente não é banhada pela água do mar, e zona úmida, que sofre influência das marés.

As coletas foram realizadas em cada ponto a uma profundidade compreendida entre 10 e $20 \mathrm{~cm}$, utilizando para o efeito, luvas e sacos estéreis. Na praia de Jaguaribe devido ao encontro da maré com o esgoto, também foi coletada água do mar. As amostras foram etiquetadas com o nome da praia e data de coleta, transportados para o laboratório em caixas térmicas contendo gelo reciclável e mantidos em geladeira até o início da análise microbiológica.

$10 \mathrm{~g}$ da amostra coletada foram submetida a um processo de suspensão no Erlenmeyer contendo $90 \mathrm{ml}$ de água fosfatada esterilizada. $\mathrm{O}$ frasco foi agitado durante 30 minutos em agitador rotativo, para garantir uma lavagem eficiente da areia. A partir deste lavado de areia, foram realizadas suspensões subsequentes, até a quarta suspensão. As amostras devidamente suspensas foram semeadas inicialmente em meio Ágar sangue e mantidas em incubação a $37^{\circ} \mathrm{C}$ por 48 horas em estufa bacteriológica.

Após a incubação foi realizada a identificação das colônias, as bactérias, foram separadas em $\alpha$-hemolítica e $\beta$ hemolítica. Posteriormente foi realizado o teste de catalase para separar os gêneros Staphylococcus e Streptococcus. No qual, os esfregaços da catalase negativas foram consideradas do gênero Streptococcus. E os esfregaços catalase positiva foram semeados em ágar manitol para confirmação da Staphylococcus aureus.

Foi realizado o teste de Gram, e as bactérias Gram negativas foram inoculadas em meio Agar EMB (Eosin Methylene Blue), Agar MacConkey e Agar TCBS (Agar de Tiossulfato, Citrato, Bílis e Sacarose) em incubação a $37^{\circ} \mathrm{C}$ por 48 horas em estufa bacteriológica. Para deteç̧ão de coliformes totais, foram realizadas diluições seriadas de $10^{-1}$ a $10^{-4}$ e as alíquotas inoculadas no meio de cultivo Caldo Lactosado contendo um tubo de Durhan, incubados por $24-48$ horas a $37{ }^{\circ} \mathrm{C}$ em estufa bacteriológica. Os tubos positivos para caldo lactosado foram inoculados em Caldo Verde Brilhante (VB) e incubados a $37^{\circ} \mathrm{C}$ em estufa bacteriológica. 
O delineamento experimental foi inteiramente casualizado com 2 tratamentos (pontos de coleta) e 6 repetições (épocas de amostragens). Os dados dos parâmetros microbiológicos coliformes totais, E. coli e enterococos foram transformados em $y$ $\mathrm{x}+1$.

\section{Resultados e Discussão}

Diante das análises das amostras coletadas na praia do Quartel (Olinda) e Jaguaribe (Itamaracá) do litoral norte de Pernambuco, foram evidenciados a presença das espécies: Escherichia coli, Klesbsiella pneumoniae Enterococcus spp Staphylococcus spp, Staphylococcus aureus, Streptococcus spp e Vibrio cholerae (Quadro 1).

Quadro 1 - Identificação dos isolados bacterianos nas praias do Quartel e Jaguaribe litoral norte de Pernambuco.

\begin{tabular}{|c|c|c|}
\hline Local & Amostras & Resultados \\
\hline \multirow[b]{2}{*}{ Praia do Quartel (Olinda) } & Coleta 1 & $\begin{array}{l}\text { Staphylococcus spp } \\
\text { Streptococcus spp }\end{array}$ \\
\hline & Coleta 2 & $\begin{array}{c}\text { Escherichia coli } \\
\text { Staphylococcus spp } \\
\text { Staphylococcus aureus } \\
\text { Streptococcus spp } \\
\text { Vibrio cholerae }\end{array}$ \\
\hline \multirow[t]{2}{*}{ Praia do Jaguaribe (Itamaracá) } & Coleta 1 & $\begin{array}{c}\text { Escherichia coli } \\
\text { Klesbsiella pneumoniae } \\
\text { Staphylococcus spp } \\
\text { Streptococcus spp } \\
\text { Vibrio cholerae }\end{array}$ \\
\hline & Coleta 2 & $\begin{array}{c}\text { Escherichia coli } \\
\text { Enterococcus spp } \\
\text { Klesbsiella pneumoniae } \\
\text { Staphylococcus spp } \\
\text { Staphylococcus aureus } \\
\text { Streptococcus spp } \\
\text { Vibrio cholerae }\end{array}$ \\
\hline
\end{tabular}

Fonte: Autores.

A E.coli e Klesbsiella pneumoniae são bactérias pertencente à família Enterobacteriaceae, abundante nas fezes humanas e de animais, sendo comumente encontrada em esgotos, efluentes, águas naturais e solos que tenham recebido contaminação fecal recente (Maciel \& Mattos, 2013).

A espécie S. aureus possui maior potencial patogênico, apresentando inúmeros fatores de virulência (Santos, 2015). Segundo Tracey (2020), o S. aureus é uma bactéria com um grande potencial patogênico, pois apresenta diversos tipos de infecções, que vão desde invasivas a doenças mediadas por toxinas, onde a gravidade da infecção depende das cepas que o humano adquire no local contaminado.

A ocorrência de espécies de bactérias foi maior nas duas coletas da praia do Jaguaribe (Itamaracá), quando comparamos com a praia do Quartel (Olinda), provavelmente devido à presença de descarga de esgoto sanitário que escorria pela areia em direção água da praia, nas suas margens foi possível enxergar bastante lixo e vegetação, o que não foi observado em Olinda. Segundo Brites (2010), a contaminação tanto da areia quanto da água do mar é gerada pelo despejo de esgoto, podendo contaminar os banhistas com microrganismos patogênicos, que podem estar presentes nas fezes humanas.

Sabendo que esse esgoto poderia ser uma possível fonte de contaminação, foram realizados dois testes na água (incidência do esgoto/maré) da praia de Jaguaribe e foram observadas, as mesmas bactérias que foram encontradas na areia. Os estudos de Goodwin et al (2012) e Yamaha et al (2012) corroboraram com estes achados, uma vez que em suas pesquisas 
foram encontrados os patógenos Staphylococcus aureus, Enterococos spp, Salmonella spp, assim como S. aureus resistente à meticilina (MRSA).

A presença de esgoto não tratado e a presença de animais e resíduos sólidos corroboram para que essa contaminação seja maior, dito isso pode-se visualizar no experimento que a areia esteja sendo contaminada pela água. Kochinski (2020) e Destro et al. (2020), concluíram em seu estudo que, a presença de animais, descarga de esgoto sanitário, mudança de estação do ano, e um grande número de banhistas contribuem para a sobrevivência e dispersão de microrganismos patogênicos em areia de praia.

Com relação a profundidade, a incidência de bactéria foi maior nas amostras superficiais $(10 \mathrm{~cm})$ tanto de praia de Jaguaribe como praia de Quartel, levando a entender que as amostra superficiais sofrem contato direto com os vetores, promovendo maior influência na contaminação de microrganismos patogênicos, consequentemente as amostras de $(20 \mathrm{~cm})$ tendem a ter uma menor taxa de microrganismos patogênicos devido a não total influência antrópica e também ao processo de banho pela maré (Figura 3 e 4). Halliday e Gast (2011) confirmam este fato em seu trabalho, pois observaram a variação na presença de bactéria com relação ao nível de profundidade levando em consideração a sua zona, além de a areia seca demonstrar contaminação superior à areia úmida.

Figura 3 - Comparação da incidência de bacias na primeira coleta nas duas praias em seus respectivos pontos/profundidade.

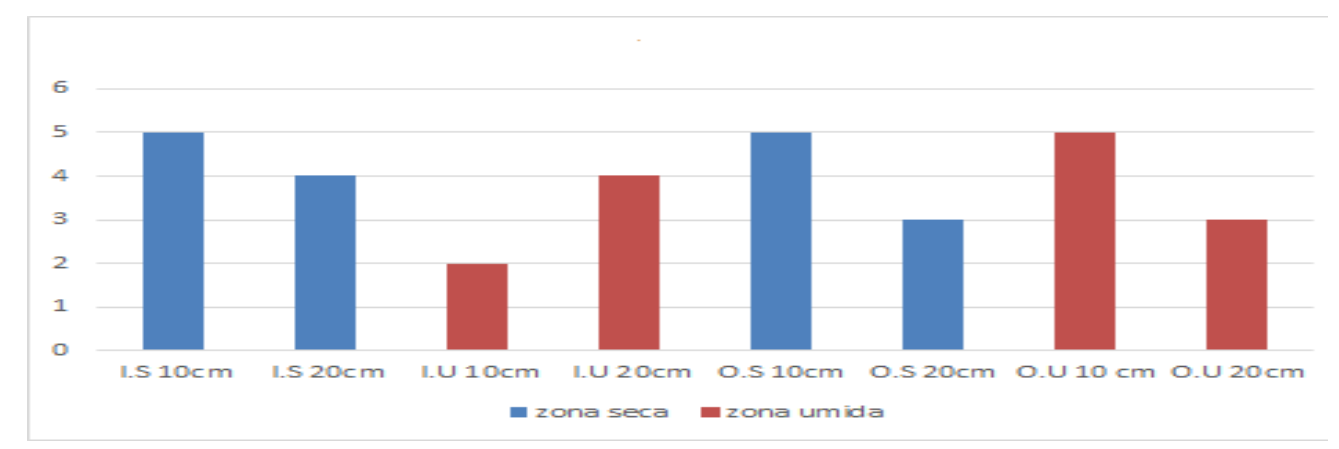

Legenda: I.S= Itamaracá seca, I.U= Itamaracá úmida, O.S= Olinda seca, O.U= Olinda úmida. Fonte: Autores.

Figura 4 - Comparação da incidência de bactérias na segunda coleta nas duas praias em seus respectivos pontos/profundidade.

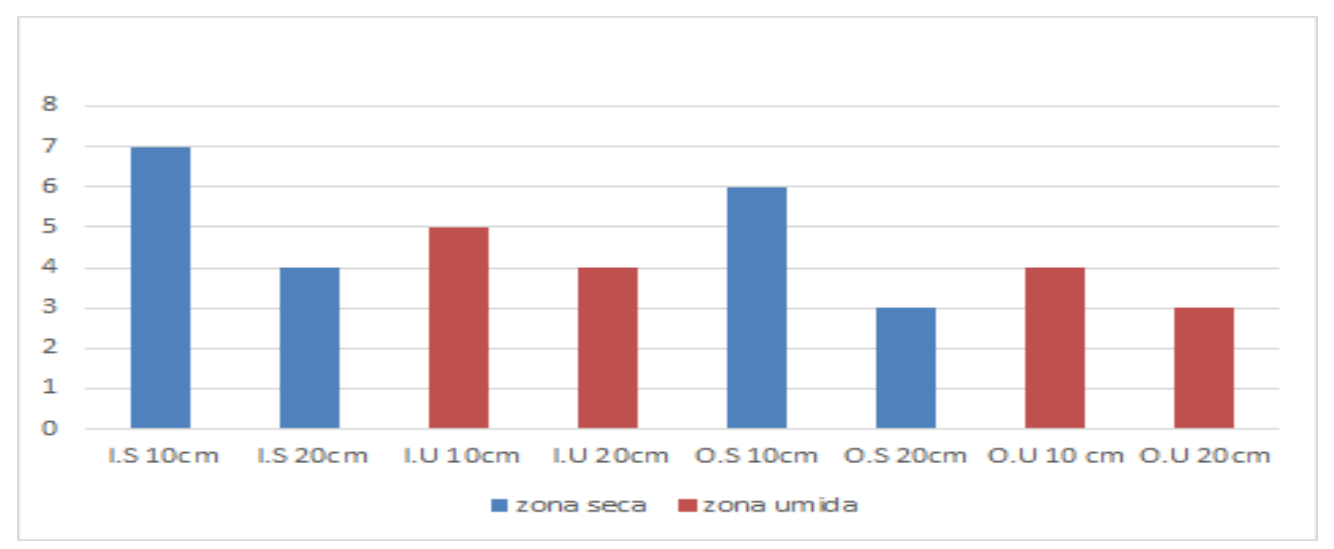

Legenda: I.S= Itamaracá seca, I.U= Itamaracá úmida, O.S= Olinda seca, O.U= Olinda úmida. Fonte: Autores.

Como relação ao coliformes totais a maior presença foi na areia seca que na areia úmida e a bactéria em maior evidência E.coli e Enterococcus spp. Uma vez que a areia molhada se encontra mais próxima do mar, a mesma sofre condição referente ao processo de "lavagem" pela água e, portanto, os patógenos tornam-se menos presentes em relação a areia seca, que 
é mais distante da maré. O nível de contaminação microbiológica na areia de Itamaracá foi maior que a contaminação na amostra de Olinda. Panagassi e Catanozi (2011) verificaram em sua pesquisa, que a disponibilidade de matéria orgânica pode ajudar na proliferação das bactérias na praia.

Assim como no trabalho de Lamparelli et al. (2015), foi detectado a presença de coliformes fecais em ambas as praias, desta forma foi possível identificar a existência de bactérias como E. coli e Enterococos, resultantes tanto da poluição humana quanto da presença de animais. Vale salientar que essas bactérias têm sido muito úteis para medir a ocorrência e grau de contaminação fecal em águas. Na pesquisa realizada por Panagassi \& Catanozi (2011), foram encontradas Coliformes totais, E.coli e $S$. aureus em grandiosa quantidade na água do mar e na areia, dentre as amostras apresentadas a bactéria Coliforme total positivou em $100 \%$ das amostras analisadas.

A classificação de uma praia em relação à qualidade é determinada pelo dado de balneabilidade, utilizando esse parâmetro para verificar a qualidade através de dados estatísticos. Além disso, este parâmetro se torna essencial para o controle e fiscalização das praias (Martins et al., 2017).

Analisando os dados de balneabilidade da Companhia Pernambucana de Recursos Hídricos (Cprh, 2021) observamos que foram feitas coletas semanais na Praia do Jaguaribe (Itamaracá) e na Praia do Quartel (Olinda). Após examinar esses dados do relatório de No 17/2021 que corresponde ao período 30/04 a 06/05 percebe-se que as praias de Jaguaribe e praia do Quartel verifica-se um maior índice de bactérias patogênicas estão impropria para banho. Os resultados obtidos no presente estudo, em ambas as praias, corroboram os dados fornecidos pelos boletins semanais emitidos por tal órgão, incluindo-se a semana na qual foram efetuadas as análises.

\section{Conclusão}

Concluiu-se que nas areias secas e úmidas das praias de Olinda e Itamaracá apresentam contaminação por agentes patogênicos. Notando-se que a praia de Itamaracá tem uma sobreposição no índice de contaminação quando comparada a de Olinda, o fator determinante está diretamente ligado ao esgoto a céu aberto, sendo ele um dos principais fatores de poluição, em conjunto com as ações antrópicas e a presença de animais. Portanto, acredita-se que é necessário um estudo de controle, onde o monitoramento e o saneamento da areia de praia sejam frequentes, para que se tenha uma certificação da qualidade do ambiente, tornando-a apropriada para o lazer.

\section{Referências}

Andrade, V. C., Zampieri, B. D., Ballesteros, E. R., Pinto, A. B., \& Oliveira, A. J. F. C. (2015), Densities and antimicrobial resistance of Escherichia coli isolated from marine waters and beach sands. Environmental Monitoring and Assessment, 187, (342), 01-10.

Boehm, A. B., Griffith, J., McGee, C., Edge, T. A., Solo-Gabriele, H. M., Whitman, R., \& Weisberg, S. B. (2009). Faecal indicator bacteria enumeration in beach sand: a comparison study of extraction methods in medium to coarse sands. Journal of applied microbiology, 107(5), 1740-1750.

Borges, R. M., Minillo, A., Lemos, E. G. M., Prado, H. F. A., \& Tangerino, E. P. (2016), Uso De Filtros De Carvão Ativado Granular Associado A Microrganismos Para Remoção De Fármacos No Tratamento De Água De Abastecimento. Revista Engenharia Sanitária E Ambiental, 21, (4), 709-720.

Brites, A. P. Z. (2010.), Enquadramento Dos Corpos De Água Através De Metas Progressivas: Probabilidade De Ocorrência E Custos De Despoluição Hídrica. Tese, Doutorado Em Engenharia, Escola Politécnica Da Universidade De São Paulo.

Cicero, L. H., Quiñones, E. M., Cunico, P., \& Santos, C. L. (2012), Contaminação Das Areias De Praias Do Brasil Por Agentes Patológicos. Revista Ceciliana, 4, (2), 44-49.

Cprh. (2021), Informativo Da Variabilidade Das Praias De Pernambuco. Agência Estadual De Meio Ambiente (Cprh). Http://Www2.Cprh.Pe.Gov.Br/Monitoramento-ambiental/Balneabilidade/Informativo-semanal/.

Destro, J. O., Rosa, V. T., Pinto, F. S. T., \& Soares, C. J. (2020), Qualidade Microbiológica Das Areias De Praia Do Litoral Norte Gaúcho. scientia Prima, Rio Grande Do Sul, 6, (1), 48-58.

França, L. F., Casagrande, J. A., \& Fortuna, J. L. (2018), Avaliação Microbiológica Das Areias E Da Água Das Praias Dos Municípios Litorâneos Que Formam A Costa Das Baleias. Rea - Revista De Estudos Ambientais (Online), 20, (1), 44-57. 
Goodwin, K. D., McNay, M., Cao, Y., Ebentier, D., Madison, M., \& Griffith, J. F. (2012). A multi-beach study of Staphylococcus aureus, MRSA, and enterococci in seawater and beach sand. Water research, 46(13), 4195-4207.

Kochinski, T., Barbosa, P., \& Romanello, L. (2020), Detecção De Bactérias Potencialmente Patogênicas Em Areias De Praças Públicas No Município De Universidade São Vitória- Paraná. Luminária, União Da Vitória, 23, (1), 27-34.

Lescreck, M. C., Petrini, R. G. G., Cortez, F. S., Santos, A. R.,Coutinho, P. O., \& Pusceddu, F. H. (2016), Análise Da Qualidade Sanitária Da Areia Das Praias De Santos, Litoral Do Estado De São Paulo. Revista Engenharia Sanitária E Ambiental, 21, (.4), 777-782.

Lamparelli, C. C., Pogreba-Brown, K., Verhougstraete, M., Sato, M. I. Z., de Castro Bruni, A., Wade, T. J., \& Eisenberg, J. N. (2015). Are fecal indicator bacteria appropriate measures of recreational water risks in the tropics: a cohort study of beach goers in Brazil? Water research, $87,59-68$.

Maciel, B. C., \& Mattos, L. P. V. (2013), A Bactéria Multirresistente Klebsiella Pneumoniae Carbapenamade (Kpc). Trabalho De Conclusão De Curso, (Faculdade De Biomedicina), Faculdades De Metropolitanas Unidas.

Martins, L. M. M., Medeiros, L. R. A., Rosas, R. A. R., \& Reis, A. L. Q. (2017), Analise Dos Parâmetros De Balneabilidade: Um Estudo De Caso Sobre As Praias Dos Municípios De João Pessoa E Cabedelo/ Pb, 5, (1).

Monteiro, D. T. L., Catter, K. M., Rocha, R. S., Filho, A. A. F., \& Vieira, R. H. S. F. (2015), Qualidade Bacteriológica Da Areia E Água De Duas Praias Do Litoral Cearense. Labomar Arquivos Em Ciências Do Mar, 48, (2), 41- 48.

Nogueira, E. M. (2016), Qualidade Sanitária Da Orla De João Pessoa-pb Com Base Em Fatores Bióticos E Abióticos, João Pessoa-pb. Trabalho De Conclusão De Curso, (Graduação Em Ciências Biológicas), Universidade Federal Da Paraíba.

Panagassi, K. A. L., \& Catanozi, C. Caracterização Bacteriológica Da Areia De Praia Do Município Estância Balneária De Praia Grande/Sp. Revista Da Universidade Ibirapuera, (2), 28-32.

Pereira, M. L. T., Soares, M. P. A., Silva, E. A., Montenegro, A. A. A., \& Souza, W. M. (2017), Variabilidade Climática No Agreste De Pernambuco E Os Desastres Decorrentes Dos Extremos Climáticos. Journal Of Environmental Analysis And Progress, 02, (04), $394-402$.

Pinto, A. B., Pereira, C. R., \& Oliveira, A. J. F. C. (2012), Densidade De Enterococcus Sp Em Águas Recreacionais E Areias De Praias Do Município De São Vicente-sp, Brasil E Sua Relação Com Parâmetros Abióticos. O Mundo Da Saúde, 36, (4), 587-593.

Santos, S. C. L. (2015), Prevalência De Staphylococcus Aureus Resistente Á Meticilina (Mrsa) Em Granjas De Suínos. Programa De Pós Graduação Em Zootecnia, (Centro De Ciências Agrárias), Universidade Federal Da Paraíba.

Silva, T. R., Parente, M. F., Moreira, L. V. L., Brigida, R. T. S. S., Watanabe, A. K.T., Almeida, R. V. C., Trindade, E. L., Siravenha, L. Q., \& Bezerra, N. V. (2020), Contaminação Ambiental Por Enteroparasitas Presentes Em Areias Na Praia Do Amor, Distrito De Outeiro, Belém, Pará, Brasil. Brazilian Applied Science Review, 4, (3), 1334-1342.

Souza, J. L., \& Silva, I. R. (2015), Avaliação Da Qualidade Ambiental Das Praias Da Ilha De Itaparica, Baía De Todos Os Santos, Bahia. Soc \& Nat, Uberlandia, 27, (3), 469-484. Doi: 10.1590/1982-451320150308.

Tracey A. T., \& Chandrashekhar G. U. (2020), Staphylococcus aureus. In: Statpearls. Statpearls Publishing, Treasure Island (Fl).

Yamahara, K. M., Sassoubre, L. M., Goodwin, K. D., \& Boehm, A. B. (2012). Occurrence and persistence of bacterial pathogens and indicator organisms in beach sand along the California coast. Applied and environmental microbiology, 78(6), 1733-1745. 